\title{
GnRH Neurons Elaborate a Long-Range Projection with Shared Axonal and Dendritic Functions
}

\author{
Michel K. Herde, ${ }^{\star}$ Karl J. Iremonger, ${ }^{\star}$ Stephanie Constantin, and Allan E. Herbison \\ Centre for Neuroendocrinology, Department of Physiology, University of Otago School of Medical Sciences, Dunedin 9054, New Zealand
}

Information processing by neurons has been traditionally envisioned to occur in discrete neuronal compartments. Specifically, dendrites receive and integrate synaptic inputs while axons initiate and conduct spikes to distal neuronal targets. We report here in mice, using morphological reconstructions and electrophysiology, that the gonadotropin-releasing hormone (GnRH) neurons that control mammalian fertility do not conform to this stereotype and instead possess a single projection structure that functions simultaneously as an axon and dendrite. Specifically, we show that the GnRH neuron projection to the median eminence to control pituitary hormone secretion possesses a spike initiation site and conducts action potentials while also exhibiting spines and synaptic appositions along its entire length. Classical axonal or dendritic markers are not detectable in the projection process. Activation of ionotropic glutamate and/or GABA receptors along the GnRH neuron projection is capable of depolarizing the membrane potential and initiating action potentials. In addition, focal glutamate application to the projection is able to regulate the width of propagating spikes. These data demonstrate that GnRH neurons elaborate a previously uncharacterized neuronal projection that functions simultaneously as an axon and dendrite. This structure, termed a "dendron," greatly expands the dynamic control of GnRH secretion into the pituitary portal system to regulate fertility.

\section{Introduction}

The gonadotropin-releasing hormone $(\mathrm{GnRH})$ neurons represent the final output cells of a hypothalamic network that controls fertility in all mammalian species (Terasawa and Fernandez, 2001; Levine, 2003; Herbison, 2006; Plant, 2008). Although the cell bodies of the GnRH neurons are scattered throughout the basal forebrain, they send projections to a highly discrete region called the median eminence to secrete GnRH into the pituitary portal circulation to regulate gonadotropin secretion (Herbison, 2006). It has long been known that GnRH neurons have a very simple bipolar morphology (Silverman et al., 1994). However, recent studies have demonstrated that $\mathrm{GnRH}$ neuron dendrites extend for surprisingly long distances over $1000 \mu \mathrm{m}$, receive substantial synaptic input, and exhibit postnatal developmental and steroid-dependent plasticity (Campbell et al., 2005, 2009; Cottrell et al., 2006; Chan et al., 2011; Ybarra et al., 2011).

Whereas the GnRH nerve terminals within the median eminence have been very well characterized, it remains curious that electron microscopic investigations over many years have failed to identify the origin of the $\mathrm{GnRH}$ neuron axon from the cell

\footnotetext{
Received Feb. 6, 2013; revised June 21, 2013; accepted June 26, 2013.

Author contributions: M.K.H., K.J.I., and A.E.H. designed research; M.K.H., K.J.I., and S.C. performed research; M.K.H., K.J.I, and A.E.H. analyzed data; M.K.H., K.J.., S.C., and A.E.H. wrote the paper.

This work was supported by the New Zealand Health Research Council and a University of Otago PhD Scholarship to M.K.H.

${ }^{*}$ M.K.H. and K.J.I. contributed equally to this work.

The authors declare no competing financial interests.

Correspondence should be addressed to Allan Herbison, Centre for Neuroendocrinology, Department of Physiology, University of Otago School of Medical Sciences, P.0. Box 913, Dunedin 9054, New Zealand. E-mail: allan.herbison@otago.ac.nz.

DOI:10.1523/JNEUROSCI.0579-13.2013

Copyright $\odot 2013$ the authors $\quad 0270-6474 / 13 / 3312689-09 \$ 15.00 / 0$
}

body (Silverman et al., 1994; Campbell et al., 2009). Recently, the origin and nature of the GnRH neuron axon has been questioned further as electrophysiological studies have identified that action potentials in $\mathrm{GnRH}$ neurons are triggered, in the most part, from within the proximal dendrite of these cells (Roberts et al., 2008; Iremonger and Herbison, 2012). This suggested the possibility that the axon may originate from the proximal dendrite rather than the cell body.

The current series of studies were initiated to establish the origin of the GnRH neuron axon. Remarkably, we have found that GnRH neurons do not elaborate axons but, instead, use the previously identified long GnRH neuron dendrites to project all the way to the median eminence whereupon they terminate by splitting into multiple nerve terminals. This unique projection functions simultaneously as an axon and dendrite to control GnRH peptide neurosecretion.

\section{Materials and Methods}

Animals. Male C57BL/6J GnRH-GFP mice (Spergel et al., 1999) were housed with $12 \mathrm{~h}$ of light and ad libitum access to food and water. Ages of animals ranged between $40-90 \mathrm{~d}$. All experimentation was approved by the University of Otago Animal Welfare and Ethics Committee. Animals were killed by cervical dislocation, the brain quickly removed, and the optic tract peeled off before gluing the neocortex to a vibratome cutting stage. The vibratome blade was positioned to just touch the caudal extent of the hypothalamus and a single $500-\mu \mathrm{m}$-thick horizontal slice prepared (Constantin et al., 2012).

Juxtacellular filling of GnRH neurons. Individual identified GnRH neurons were patched with a whole-cell pipette solution containing $0.2 \%$ Neurobiotin (SP-1120; Vector Laboratories) and a tight seal (>200 $\mathrm{M} \Omega$ ) obtained. Voltage steps of $100 \mathrm{mV}$ and $60 \mathrm{~ms}$ duration were delivered at $10 \mathrm{~Hz}$ through an Axoclamp 2B amplifier (Molecular Devices) for 30 $120 \mathrm{~min}$. After filling, slices were fixed in $4 \%$ paraformaldehyde in $0.1 \mathrm{M}$ 


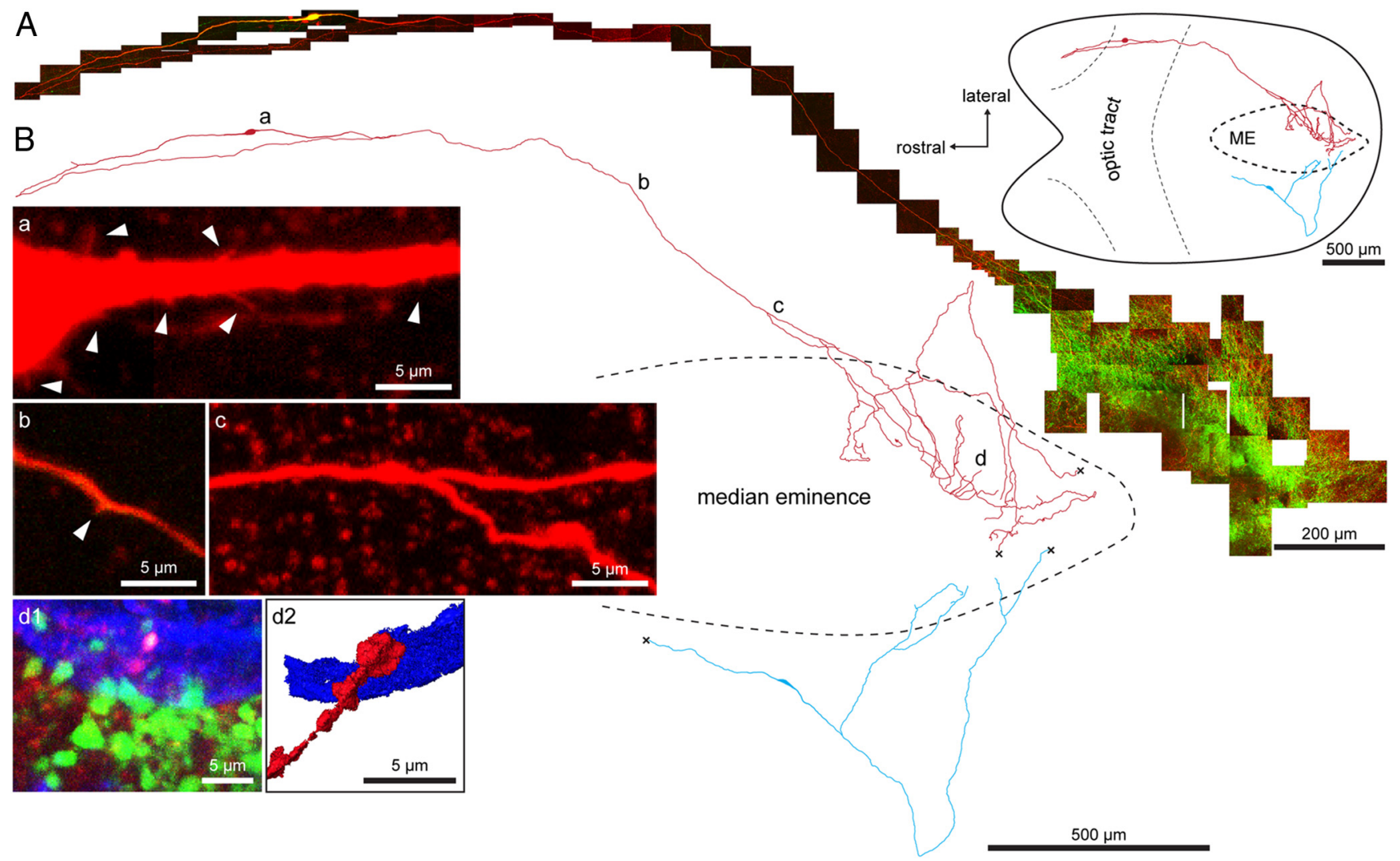

Figure 1. Cell filling of individual GnRH neurons reveals a unique projection to the median eminence (ME). $A$, Montage of confocal z-projections of GnRH neuron (yellow/red) in the anterior hypothalamic area projecting to the ME, which is labeled green by the dense fiber plexus of the other GFP-expressing GnRH neuron fibers. The top inset right shows the location of the neuron within the horizontal brain slice preparation. The optic tract was removed during dissection. $\boldsymbol{B}$, Camera lucida-like reconstruction of two GnRH neurons projecting to the median eminence; one shown in $\boldsymbol{A}$ above (red) and another with its cell body located close to the median eminence (blue). $\boldsymbol{a}-\boldsymbol{d}$, Positions of the respective high-magnification pseudocolored insets. Red, Neurobiotin; green, transgene GFP; blue, B. simplicifolia Lectin 1 blood vessel label. Arrowhead in $\boldsymbol{b}$ indicates a spine. d1, Filled GnRH neuron terminal (white/pink) among terminals of other GnRH neurons (green) in the external zone of the median eminence juxtaposed to a blood vessel (blue). $\boldsymbol{d} \mathbf{2}$, Isosurface rendering of $\boldsymbol{d} \mathbf{1}$ demonstrating the close proximity between filled terminal and blood vessel. " $\mathrm{X}$ " in $\boldsymbol{B}$ indicates fibers that continue but could not be photographed.

phosphate buffer, $\mathrm{pH} 7.6$, at $4^{\circ} \mathrm{C}$ for $2-12 \mathrm{~h}$ depending on the subsequent protocol.

Primary antibodies. The following antibodies were used in this study and references are provided for publications that have described their staining patterns and specificity. $\beta$-3-Tubulin was used as a general neuronal marker (1:1000; R\&D Systems, MAB1195, lot HGQ01) (Moody et al., 1989). Dendritic markers were MAP2 (1:1,000; Sigma Aldrich, M4403, lot 111K4806) (Huber and Matus, 1984), dephosphorylated heavy neurofilament (1:500; Sternberger Monoclonals, SMI32) (Sternberger and Sternberger, 1983), and KIF17 (1:100; Abcam, ab11261, lot 721005) (Setou et al., 2000; Chung et al., 2009). Axonal markers used were Tau1 (1:500; Millipore, MAB3420, lot LV1563313) (Binder et al., 1985) and phosphorylated heavy neurofilament (1:500; Sternberger Monoclonals, SMI31) (Sternberger and Sternberger, 1983). Green fluorescent protein (GFP) signal was amplified using a GFP antibody (1: 5000; Invitrogen, A6455, lot 71B1). Initial segments were labeled with a monoclonal Ankyrin G antibody (1:50; Santa Cruz Biotechnology, sc12719, lot D1309) (Van Wart et al., 2007). Synaptobrevin 2 (VAMP2) was used as a presynaptic marker (1:300; Synaptic Systems, \#104202, lot 104202/20) (Witkovsky et al., 2008).

Immunohistochemistry on Neurobiotin-filled cells in acute slices. Brains slices for Ankyrin G or VAMP2 labeling were fixed for $2 \mathrm{~h}$ or $12 \mathrm{~h}$, respectively, in $4 \%$ paraformaldehyde. They were subsequently washed $3 \times 30 \mathrm{~min}$ in Tris-buffered saline (TBS), $\mathrm{pH} 7.6$, to remove residual aldehydes. Incubation of Ankyrin G and VAMP2 antibodies was performed in incubation solution $(0.25 \%(\mathrm{w} / \mathrm{v})$ bovine serum albumin (BSA) and $0.6 \%(\mathrm{w} / \mathrm{v})$ Triton $\mathrm{X}-100$ in TBS, $\mathrm{pH} 7.6$, with $2 \%(\mathrm{v} / \mathrm{v})$ normal serum at $4^{\circ} \mathrm{C}$ for $48 \mathrm{~h}$. After $3 \times 30$ min washes in TBS, secondary antibodies (donkey anti-mouse DyLight 549; Jackson ImmunoResearch,
\#715-506-150, 1:200; goat anti-rabbit Alexa Fluor 568, Invitrogen, A11011, 1:200) and the far-red streptavidin Alexa Fluor 647 (Invitrogen, S11226, 1:200) were incubated with the sections in incubation solution at room temperature for $4 \mathrm{~h}$. All specimens were coverslipped in AquaPoly/Mount (Polysciences). The omission of primary antibodies or incubation with inappropriate secondary antibodies resulted in a complete absence of immunoreactivity in control experiments. Pre-adsorption of the VAMP2 antibody was undertaken by incubation with $1 \mu \mathrm{M}$ VAMP2 antigen (Synaptic Systems) for $48 \mathrm{~h}$ at $4 \mathrm{C}$.

Blood vessel labeling. Slices were washed as described above followed by incubation with Rhodamine Bandeiraea simplicifolia Lectin 1 (Vector Laboratories, RL-1102, 1:500) and streptavidin Alexa Fluor 647 (Invitrogen, S11226, 1:200) in incubation solution at room temperature for $4 \mathrm{~h}$. Slices were subsequently rinsed $3 \times 30 \mathrm{~min}$ in TBS and mounted as described above.

Immunohistochemistry on perfusion-fixed brains. Adult male GnRHGFP animals were deeply anesthetized using pentobarbital $(30 \mathrm{mg} / 100 \mathrm{~g}$ body weight) and were transcardially perfused with $15 \mathrm{ml}$ of cold $4 \%$ paraformaldehyde. Brains were removed immediately and immersion fixed at room temperature for $1 \mathrm{~h}$. Subsequently, brains were cryoprotected in $30 \%(\mathrm{w} / \mathrm{v})$ sucrose in TBS at $4^{\circ} \mathrm{C}$ overnight. Sections of $30 \mu \mathrm{m}$ thickness were cut on a freezing stage microtome and residual aldehydes were removed by washing sections in TBS for $3 \times 10 \mathrm{~min}$. Primary antibody incubation was performed at $4^{\circ} \mathrm{C}$ for $\sim 48 \mathrm{~h}$ in incubation solution $(0.3 \%(\mathrm{w} / \mathrm{v})$ Triton X-100 and $0.25 \%(\mathrm{w} / \mathrm{v})$ BSA in TBS, pH 7.6, with $2 \%(\mathrm{v} / \mathrm{v})$ normal serum of the species the secondary antibodies had been raised in. Again, the tissue was rinsed $3 \times 10 \mathrm{~min}$ in TBS and secondary antibodies (goat anti-rabbit and goat anti-mouse conjugated with Alexa Fluor 488 and 568 (1:200 to 1:1,000; Invitrogen)) were incu- 


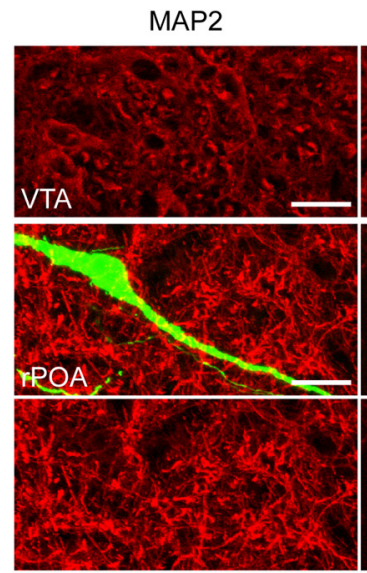

Tau1

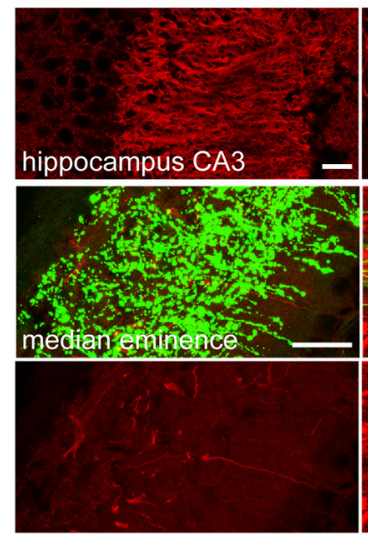

dephosphorylated NF

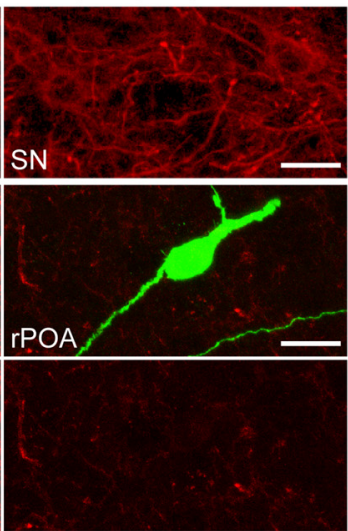

phosporylated NF
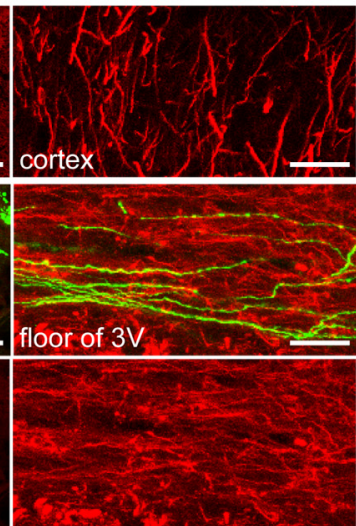
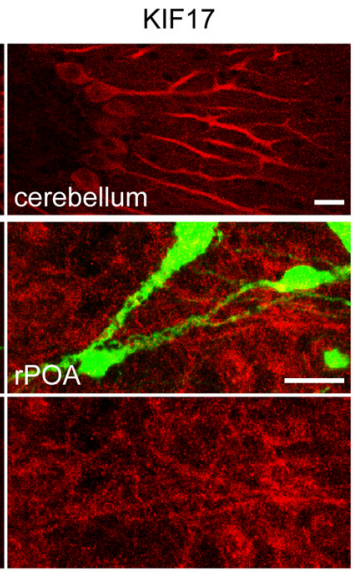

$\beta 3$ Tubulin
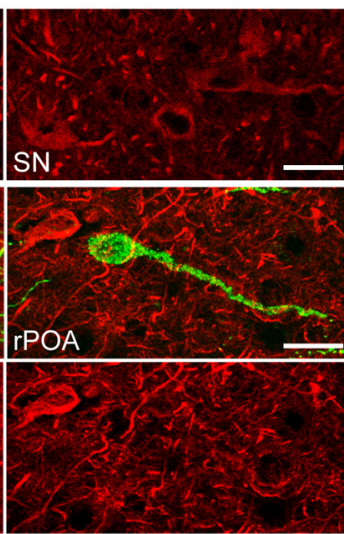

Figure 2. GnRH neuron processes do not label for classical axonal or dendritic markers. All markers (red label) labeled appropriate neuronal compartments in various other brain areas (top) but did not localize to GnRH neurons (green, middle). The bottom part of the same field, without GnRH GFP, is given for each marker to show that it is not expressed by GnRH neurons. Dendritic markers used were microtubule-associated protein 2 (MAP2) and dephosphorylated neurofilament and kinesin-like protein 17 (KIF17). Axonal markers were Tau1 and phosphorylated neurofilaments (NF). The general neuronal marker $\beta$-3-tubulin did not label GnRH neurons. 3V, third ventricle; rPOA, rostral preoptic area; SN, substantia nigra; VTA, ventral tegmental area. Scale bars: $10 \mu \mathrm{m}$.

bated in incubation solution at room temperature for 60-90 $\mathrm{min}$. After a final set of washes for $3 \times 10$ min sections were mounted on gelatincoated slides, dried, and subsequently coverslipped using Aqua-Poly/ Mount (Polysciences).

Confocal microscopy and image analysis. Specimens were photographed using a Zeiss LSM 510 confocal microscope with LSM 510 software (version 3.2). Image stacks were acquired at $0.4 \mu \mathrm{m}$ intervals with a $40 \times / 1.3$ Plan Neofluar objective using $3 \times$ zoom and the pinhole adjusted to 1 Airy unit. Maximum intensity projections of stacks and other image analyses were done using ImageJ (version 1.46a). Montages of projected stack images and adjustments of brightness levels were made in Adobe Photoshop CS4; camera lucida-like reconstructions were manually drawn in Adobe Illustrator CS4. Isosurface renderings were done in Amira 5.3 (Visage Imaging). For figures, Alexa Fluor 647 was represented as red while DyLight 549 and Alexa Fluor 568 were pseudocolored as cyan or magenta. For the quantitation of VAMP2 appositions, the criteria for determining an apposition were the following: (1) its punctate appearance with intensity above background, (2) immediate juxtaposition or slight overlap between dendritic and VAMP2 signal, (3) center of VAMP2 puncta not overlapping with dendritic label (to exclude that it is located within the dendrite and thus a GnRH neuron release site), and (4) the VAMP2 puncta appears in at least two subsequent images within the confocal stack.

In vitro recordings. Brain slices were perfused with artificial CSF (ACSF) at $25^{\circ} \mathrm{C}$ in a recording chamber under an Olympus FV1000 confocal microscope. ACSF consisted of the following (in $\mathrm{mm}$ ): $118 \mathrm{NaCl}, 3$ $\mathrm{KCl}, 11 \mathrm{D}$-glucose, $10 \mathrm{HEPES}, 25 \mathrm{NaHCO}_{3}, 2.5 \mathrm{CaCl}_{2}$, and $1.2 \mathrm{MgCl}_{2}$.
Recordings were obtained from GnRH neurons in the anterior hypothalamic area (AHA) with projections to the median eminence. The pipette solution for whole-cell recording consisted of the following (in mM): 140 potassium gluconate, $8 \mathrm{NaCl}, 10$ HEPES, 10 Trisphosphocreatine, $4 \mathrm{MgATP}, 0.4 \mathrm{NaGTP}$, and 0.04 Alexa Fluor 555 hydrazide. Cells were held close to $-60 \mathrm{mV}$ in current clamp for consistency across experiments. Simultaneous looseseal on cell recordings were performed from the soma and median eminence projection with patch electrodes filled with ACSF as previously described (Iremonger and Herbison, 2012).

Glutamate and GABA were puff applied with patch pipettes filled with ACSF and 500 $\mu \mathrm{M}$ glutamate or $100 \mu \mathrm{M}$ GABA. Picrotoxin $(100 \mu \mathrm{M})$ and $\mathrm{D}$-serine $(10 \mu \mathrm{M})$ were included in the bath ACSF for experiments with glutamate puffs to block $\mathrm{GABA}_{\mathrm{A}}$ transmission and facilitate the activation of NMDA receptors, respectively. Glutamate puff responses could be blocked with the AMPA and NMDA receptor antagonists whereas GABA puff responses could be blocked with $\mathrm{GABA}_{\mathrm{A}}$ receptor antagonists. Puffs were controlled by a picospritzer (World Precision Instruments) and were delivered at low pressure ( $\sim 2$ psi) for $500 \mathrm{~ms}$. The effective radius of the puffs was $60-80 \mu \mathrm{m}$.

Channelrhodopsin stimulation and uncaging. Channelrhodopsin (ChR2) stimulation was performed in Vgat-ChR2; GnRH-GFP transgenic mice that have ChR2 expression targeted to GABAergic neurons (Zhao et al., 2011). A $100 \mu \mathrm{m}$ optic fiber was placed rostral and lateral to the median eminence and $2 \mathrm{~ms}$ flashes of $473 \mathrm{~nm}$ light were delivered by a DPSS laser (IkeCool). Mean laser power used was $4 \mathrm{~mW}$. Light-evoked GABA synaptic currents were blocked with $100 \mu \mathrm{M}$ picrotoxin confirming the specificity of ChR2 stimulation. Synaptic currents were recorded in whole-cell mode with a high chloride pipette solution consisting of the following (in $\mathrm{mM}$ ): $130 \mathrm{KCl}, 10 \mathrm{HEPES}, 2 \mathrm{MgATP}, 0.2 \mathrm{NaGTP}$, and 0.04 Alexa Fluor 555.

Glutamate uncaging was performed with the $405 \mathrm{~nm}$ laser line of an Olympus FV1000 confocal microscope. Methoxy-7-nitroindolinyl-(MNI)glutamate-trifluoroacetate (Femtonics) was dissolved in ACSF and continually puff applied to the slice above the uncaging site at a concentration of $5 \mathrm{~mm}$. Uncaging was performed by line scanning a 5-10 $\mu \mathrm{m}$ region immediately adjacent and parallel to the projection process 92 times over $140 \mathrm{~ms}$. No depolarization could be recorded if the uncaging scan was moved $20 \mu \mathrm{m}$ away from the recorded process. Picrotoxin $(100 \mu \mathrm{M})$ was included in the bath to block $\mathrm{GABA}_{\mathrm{A}}$ receptors.

Electrophysiological recordings were collected with a Multiclamp 700B amplifier (Molecular Devices), using a low-pass filter at $1 \mathrm{kHz}$ and digitized with the Digidata 1440A (Molecular Devices) at 50-100 kHz. All electrophysiological data were analyzed with Clampex10 software (Molecular Devices).

Statistics. All data are presented as mean \pm SEM. Statistical analyses were performed with the Wilcoxon matched-pairs signed rank test; $p<$ 0.05 was accepted as statistically significant.

\section{Results}

Identification of a unique $\mathrm{GnRH}$ neuron projection to the median eminence

To determine the entire morphology of the GnRH neuron we used a new horizontal brain slice preparation from adult male 


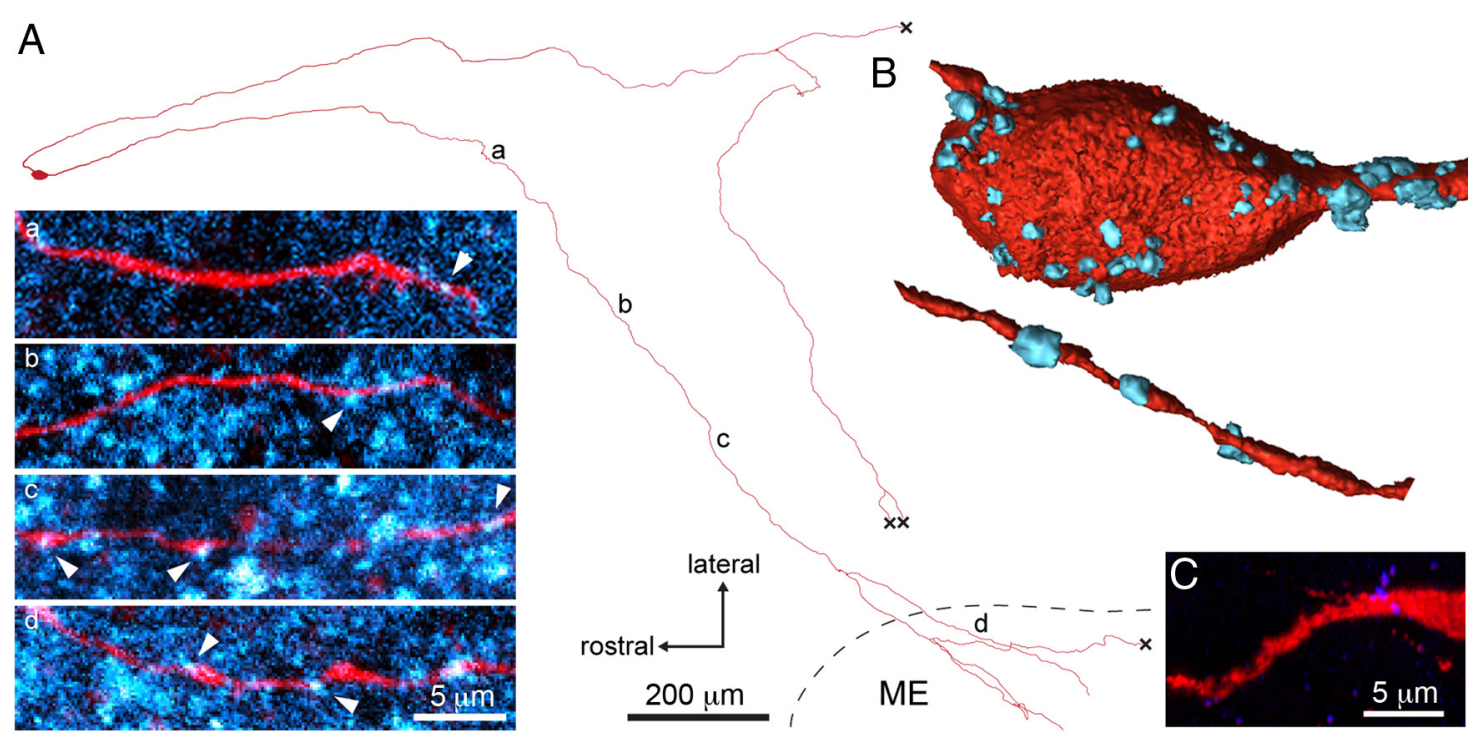

Figure 3. The GnRH neuron projections to the median eminence receive synaptic input throughout their length. $A$, Camera lucida-like reconstruction of a filled GnRH neuron (red) projecting to the median eminence (ME), double-labeled with synaptobrevin 2 (VAMP2; pseudocolored cyan) antibodies to show putative synaptic inputs. $\boldsymbol{a}$ - $\boldsymbol{d}$, Positions of single-plane confocal highmagnification. Multiple VAMP2 puncta (arrowheads) can be observed along the projection and into the ME. $\boldsymbol{B}$, Isosurface renderings of the cell body (top) and the distal projection (bottom) showing putative synaptic inputs positive for VAMP2 labeling (cyan). C, VAMP2 pre-adsorption control.

GnRH-GFP transgenic mice that maintains the projections of AHA GnRH neuron cell bodies to the median eminence intact (Constantin et al., 2012). Individual GnRH neurons were visualized by their GFP fluorescence and filled with Neurobiotin by single-cell electroporation. After fixation and processing for histochemistry, the entire morphology of individual GnRH neurons was reconstructed using confocal microscopy. Consistent with previous reports (Campbell et al., 2005, 2009) we found that $\mathrm{GnRH}$ neurons were generally bipolar with two long, relatively unbranched processes decorated with spines. Remarkably, we observed that all GnRH neurons reconstructed (17 cells from 12 mice), including GnRH neurons located adjacent to the median eminence, projected at least one of these dendrites directly into the median eminence (Fig. $1 A, B$ ). Upon entering the median eminence the process branched extensively (Fig. $1 A, B$ ) and formed terminals that were juxtaposed to blood vessels (Fig. $1 B d)$. We found no evidence for regressed axon-like structures in AHA GnRH neurons. In the majority of cases (60\%), the other process emanating from the cell body turned 180 degrees after a variable distance and then also projected in the direction of the median eminence (Figs. 1A, B, Fig. 4).

\section{Morphological characterization of the GnRH neuron projection to the median eminence}

The cell-filling experiment above identified what had previously been considered GnRH neuron dendrites (Campbell et al., 2005) projecting into the median eminence to form $\mathrm{GnRH}$ nerve terminals. This highly unusual situation led us undertake a further series of experiments to establish their axonal or dendritic identity.

First, we performed dual immunohistochemistry for classical axonal or dendritic markers in the $\mathrm{GnRH}$ neuron projections. Surprisingly, despite normal staining patterns in other brain regions examined, GnRH-GFP neurons did not colocalize with the general neuronal marker $\beta$-3-tubulin, or the dendritic markers microtubule-associated protein 2 , dephosphorylated heavy neurofilament and kinesin-like protein 17 (Fig. 2). Likewise, GnRH neuron processes did not colocalize with the classical axonal markers axonal phosphorylated heavy neurofilament or Tau1 (Fig. 2). Together, these results suggested that GnRH neurons extend a rather unique projection structure that is not typical of dendrites or axons of other CNS neurons.

We noted that the GnRH neuron processes to the median eminence exhibited spines along much of their projection (Fig. $1 B b$ ), indicative of a dendritic nature. To assess more generally the possibility of synaptic inputs occurring along the projection to the median eminence, individual GnRH neurons were filled with Neurobiotin and their relationship to presynaptic boutons visualized using an antibody directed against the SNARE protein synaptobrevin 2 (VAMP2). Multiple antibodies directed against various presynaptic and postsynaptic markers were tested in this immersion-fixed brain slice preparation with VAMP2 being the only one found to provide a workable and specific signal. As expected, VAMP2 was highly abundant within the brain as diffuse spots of immunoreactivity (Fig. $3 A$ ) that were absent in no primary antibody, and almost completely absent in preadsorption control experiments (Fig. 3C). Using confocal analysis, VAMP2-positive boutons were found apposed to the whole extent of the GnRH neuron projection (Fig. $3 A$ ) up to and including elements within the median eminence (Fig. $3 A d$ ). Quantitation of VAMP2 boutons showed a mean of $35.3 \pm 7.4$ appositions on the first $100 \mu \mathrm{m}$ of the proximal processes compared with $10.7 \pm 2.8$ appositions on the distal $100 \mu \mathrm{m}$ of the process before it entered the median eminence ( $n=3$ neurons; Fig. $3 A$ ). VAMP2 was also identified within filled $\mathrm{GnRH}$ neurosecretory terminals apposed to blood vessels (data not shown).

It has previously been reported that $\mathrm{GnRH}$ neurons can initiate action potentials in their proximal dendrite (Roberts et al., 2008; Iremonger and Herbison, 2012). We therefore determined specifically whether the GnRH neuron projection to the median eminence contained a spike initiation site by filling individual GnRH neurons with Neurobiotin and performing immunohistochemistry for the initial segment marker Ankyrin G (Kordeli et al., 1995). Ankyrin G immunoreactivity existed as large numbers of thin "stripes" within the brain slice and was absent upon omission of the primary antibody (Fig. 4b,c). In nine filled GnRH 

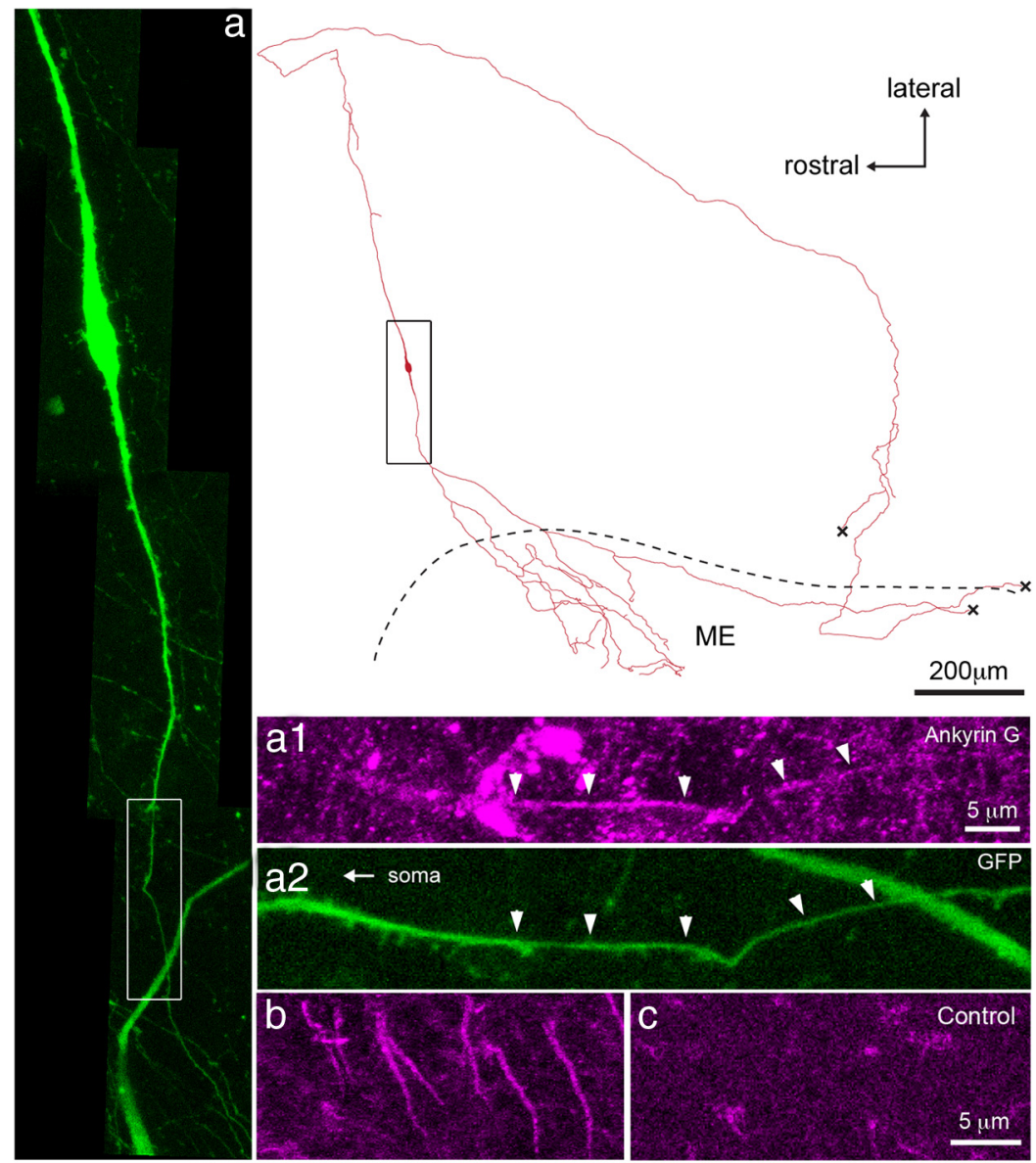

Figure 4. The GnRH neuron projections to the median eminence express the spike initiation site marker Ankyrin G. Camera lucida-like reconstruction of a filled GnRH neuron in which both projections innervate the median eminence and an Ankyrin G-positive initial segment exists in the direct projection to the median eminence (ME). Black box indicates approximate area shown to the left. $\boldsymbol{a}$, GFP-expressing GnRH neuron with white box showing area highlighted to right. $\boldsymbol{a} 1$, Ankyrin $\mathrm{G}$ immunoreactivity pseudocolored magenta. a2, Endogenous GFP label with arrowheads indicating the location of overlap with the Ankyrin $G$ signal above. Note that spines exist proximal, within, and distal to the initial segment. $\boldsymbol{b}$, The short "stripes" of Ankyrin G label, seen here in the neocortex, are absent when the primary antibody is omitted as seen in c. Note that the second dendrite of this neuron enters the median eminence as well. " $X$ " in reconstruction indicates fibers that continue but could not be photographed. neurons including labeling for Ankyrin G. Four dopaminergic neurons from two mice were reconstructed and each found to exhibit a clear dendritic tree comprised of thick processes decorated with spines, and a separate thin axonal projection devoid of spines that branched extensively both before and within the median eminence (Fig. 5). Ankyrin G was localized to only the proximal section of the axon in each of the four dopaminergic neurons (Fig. 5).

\section{Electrophysiological characterization of the GnRH neuron projection to the median eminence}

The morphological characterization above indicated that the GnRH neuron projection to the median eminence may receive synaptic input along its full length. To provide further evidence for this, we determined with electrophysiology the ability of the GnRH neuron projection to respond to the classic amino acid neurotransmitters GABA and glutamate. These experiments were undertaken by filling live GnRH neurons in the horizontal brain slice preparation with Alexa Fluor 555 and following their projection into the median eminence (Fig. 6A). The processes of GnRH neurons with cell bodies located $>1000 \mu \mathrm{m}$ from the median eminence could not be followed all the way to the median eminence as they traveled too deep in the acute brain slice to visualize. Because of this, we chose to record from AHA GnRH neuron soma closer to the median eminence $(<800 \mu \mathrm{m}$ away) for the majority of electrophysiological experiments. neurons, Ankyrin G immunoreactivity was found localized to a short segment of the GnRH neuron projection heading directly to the median eminence (Fig. 4). This was located $89 \pm 30 \mu \mathrm{m}$ from the soma and had a length of $34 \pm 3 \mu \mathrm{m}$ (Fig. 4) and we noted multiple spines present around and within the initial segment (Fig. 4a1). The location of Ankyrin G is in agreement with previous electrophysiological evidence for the site of spike initiation in one proximal dendrite of each GnRH neuron (Iremonger and Herbison, 2012).

Together, these studies indicated that the GnRH neuron projection to the median eminence does not express classical axonal or dendritic markers. It does, however, have spines and immunohistochemical evidence of presynaptic terminals along its length, while also possessing a spike initiation site. This suggested that this unusual projection functions both as an axon to conduct action potentials and also as a dendrite receiving synaptic input.

We determined whether this morphology was unique to GnRH neurons or, potentially, a general feature of all hypophysiotropic neuroendocrine cells. Arcuate nucleus dopamine neurons from tyrosine hydroxylase (TH)-GFP mice were filled with Neurobiotin and reconstructed in the same manner as GnRH
GnRH neuron projections to the median eminence have functional glutamate and $\mathrm{GABA}$ receptors

To assess whether the projection into the median eminence possessed functional receptors for neurotransmitters, we performed whole-cell recordings at the soma and locally puff applied either glutamate $(500 \mu \mathrm{M})$ or GABA $(100 \mu \mathrm{M})$ at the soma and at different distances $(100-800 \mu \mathrm{m})$ along the process using a picospritzer. The effective radius of these puffs was determined to be 60-80 $\mu \mathrm{m}$. Glutamate produced depolarizations when focally applied to the soma $(9.0 \pm 3.1 \mathrm{mV}, n=4$ neurons $)$ or along the projection $(7.4 \pm 1.5 \mathrm{mV}$, mean distance $=281 \pm 54 \mu \mathrm{m}, n=14$ sites, 8 neurons; Fig. $6 B$ ). Importantly, GnRH neuron projections that were within the lateral edges of the median eminence were also responsive to focal glutamate puffs $(6.5 \pm 1.7 \mathrm{mV}, n=8$ sites; Fig. $6 B$, red dots). Focal GABA puffs on GnRH neuron projections, including the lateral edges of the median eminence, also produced depolarizations $(9.3 \pm 1.8 \mathrm{mV}, n=13$ sites, $n=11$ neurons; Fig. $6 C$, red dots). Together, these data show that the $\mathrm{GnRH}$ neuron projection into the median eminence is responsive to both glutamate and GABA. The responses to these neurotransmitters got smaller at more distal locations from the cell body, 

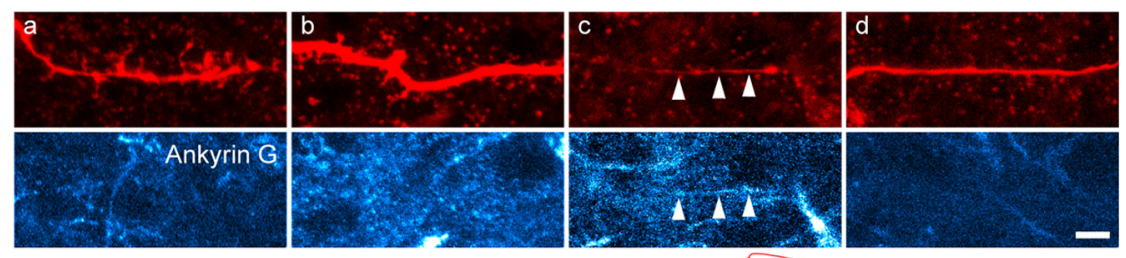

\section{TH-GFP neuron}

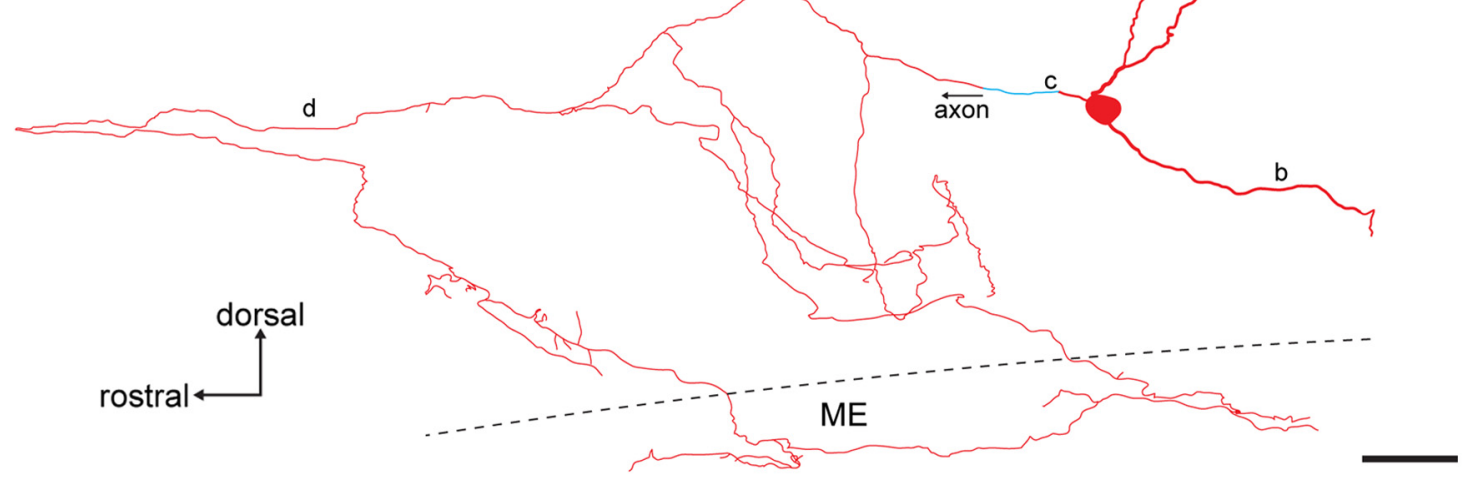

Figure 5. Neuroendocrine dopaminergic neurons observed in TH-GFP mice in the arcuate nucleus exhibit typical dendrites and an axonal projection to the median eminence (ME). Camera lucida-like reconstruction of a Neurobiotin-filled neuroendocrine dopaminergic neuron (red) from a sagittal slice with three dendrites and a separate axon that enters the ME. The relatively short, thick dendrites bear multiple long spines $(\boldsymbol{a}, \boldsymbol{b})$, are confined to the arcuate nucleus, and do not colocalize with Ankyrin $\mathrm{G}$ label (pseudocolored cyan; bottom). The thin axon has an Ankyrin G-positive initial segment shortly after leaving the soma (c, arrowheads), does not exhibit spines $(\boldsymbol{d})$, and projects to the ME.
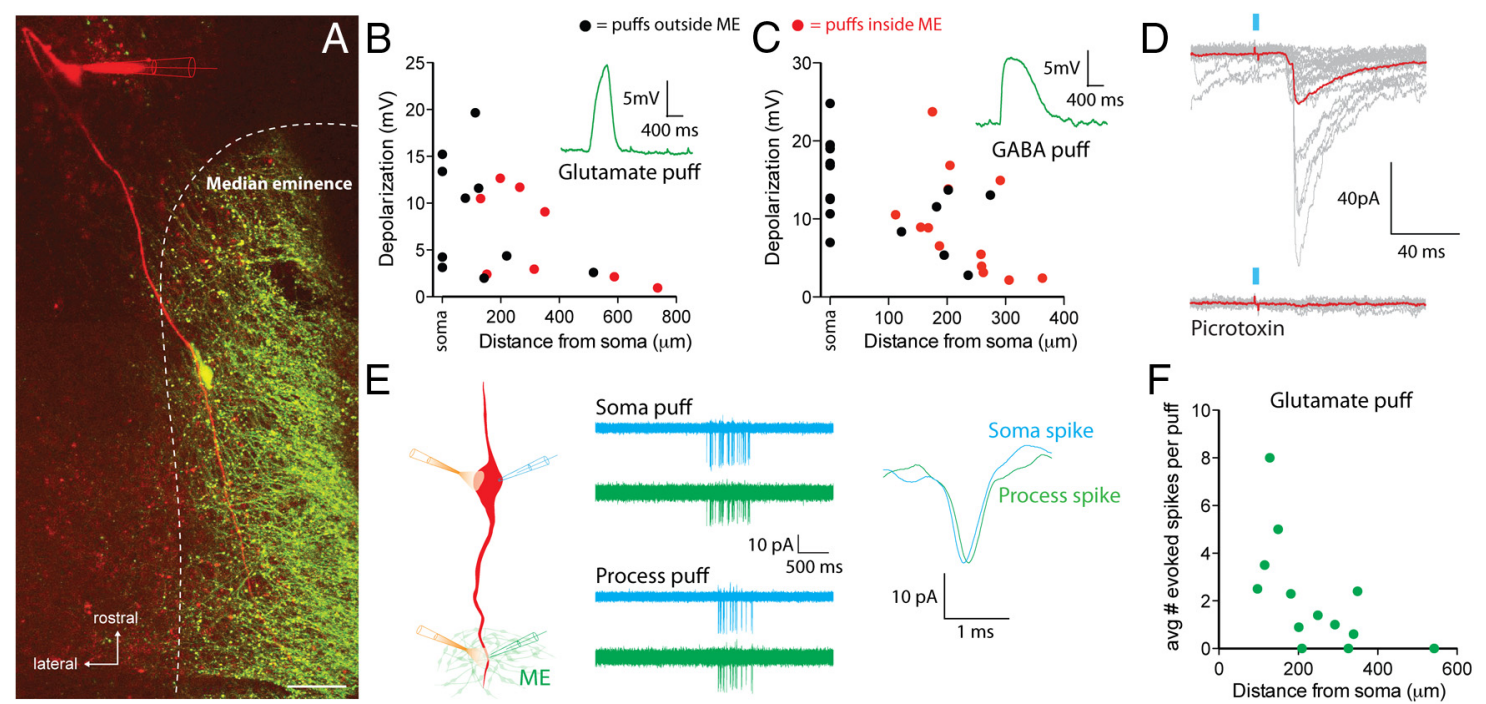

Figure 6. Median eminence projecting processes integrate synaptic signals to regulate excitability. $A$, Image of a GnRH neuron filled with Alexa Fluor 555 (red) via the recording electrode among other GnRH neuron elements (green) including a GnRH neuron cell body on the edge of the median eminence adjacent to the filled fiber in a GnRH-GFP brain slice. Scale bar represents $20 \mu \mathrm{m}$. B, $\boldsymbol{C}$, Peak depolarization evoked by puff application of glutamate $(\boldsymbol{B})$ or GABA $(\boldsymbol{C})$ at different distances along the $\mathrm{GnRH}$ neuron process. Black dots, puff sites outside of the median eminence; red dots, puff sites within the lateral aspect of median eminence. Insets are representative responses. $D$, Flashes of $473 \mathrm{~nm}$ light ( $2 \mathrm{~ms}$, blue bars) in the region around the median eminence evoke fast synaptic currents in GnRH neurons from Vgat-ChR2;GnRH-GFP mice that are blocked with the GABA $A_{A}$ receptor antagonist picrotoxin (100 $\left.\mu \mathrm{M}\right)$. $\boldsymbol{E}$, Left, Experimental setup. Middle, Representative on-cell recording from the soma (blue traces) and $181 \mu \mathrm{m}$ along the projection process (green traces). Traces are 10 trials overlaid. Puff application of glutamate to the soma or projection process elicited a burst of action potentials at both recording sites. Right, Example of a spike recorded at the soma and process after process glutamate puff showing the small latency difference. $\boldsymbol{F}$, The average number of action potentials evoked with a glutamate puff onto the projection process decreased at more distal sites.

which is consistent with electrotonic decay of these subthreshold potentials as they propagate back to the soma.

While the above experiments indicate that GnRH neuron projections have functional postsynaptic glutamate and GABA receptors, these experiments do not address whether there are functional synapses. To answer this question we crossed GnRHGFP mice with the VGAT-ChR2 mouse line (Zhao et al., 2011). Whole-cell recordings were performed from GnRH neurons located in the AHA $>1000 \mu \mathrm{m}$ from the median eminence. A 100 $\mu \mathrm{m}$ diameter optic fiber connected to a $473 \mathrm{~nm}$ blue laser was placed above the slice close to the median eminence and flashes of blue light were used to elicit action potentials in channelrhodopsin-expressing GABAergic neurons. Importantly, the optic fiber was positioned such that light flashes were directed away from the cell body of the recorded GnRH neuron. Two millisecond flashes of $473 \mathrm{~nm}$ light evoked fast synaptic currents in 5 of $6 \mathrm{GnRH}$ neurons tested (average amplitude $77 \pm 48 \mathrm{pA}$, $n=5$; Fig. $6 D$ ). These synaptic currents were blocked with 100 $\mu \mathrm{M}$ picrotoxin confirming they were due to the activation of $\mathrm{GABA}_{\mathrm{A}}$ receptors. 


\section{Activation of receptors on the GnRH neuron projection controls cellular excitability}

To determine whether the membrane depolarizations observed above were sufficient to regulate the firing of $\mathrm{GnRH}$ neurons, we recorded spiking activity with the noninvasive loose-patch technique. Loose-patch recordings were simultaneously performed at the soma and from the process projecting toward the median eminence. Glutamate was then puffed onto either the soma or distal process (mean distance $244 \pm 35 \mu \mathrm{m}$ from the soma, range 97-542 $\mu \mathrm{m}, n=13$ neurons) and the impact on spiking activity was assessed (Fig. 6E). Recordings from the GnRH neuron projections confirmed that these processes reliably propagate fast action potentials into the median eminence (Fig. $6 E$ ). Glutamate puffs onto the projection process generated spikes in the majority of neurons tested ( 10 of 13; Fig. $6 F$ ) but did not change the site of spike initiation based on comparing the latency of spikes recorded from the soma and the projection process (soma puff spike latency $=0.207 \pm 0.045 \mathrm{~ms}$; projection puff spike latency $=$ $0.234 \pm 0.049 \mathrm{~ms}, n=10$ neurons, $p>0.05)$. In addition, spikes were always observed at both recording locations indicating that spike conduction between the projection process and soma was faithful.

\section{Modulation of action potential dynamics by glutamate receptors on the GnRH neuron projection}

In addition to generating action potentials, we tested whether activation of local glutamate receptors could modify the conduction of spikes as they pass down the projection toward the median eminence. Whole-cell recordings were performed at the $\mathrm{GnRH}$ neuron soma while on-cell recordings were performed on the process projecting toward the median eminence (mean distance $180 \pm 12 \mu \mathrm{m}$ from the cell body, $n=8$ neurons). To mimic a burst of synaptic activation, MNI-glutamate was uncaged locally next to the projection recording site (amplitude of uncaging EPSP $2.6 \pm 0.7 \mathrm{mV}, n=8$ neurons). To test the effect of glutamate receptor activation on spike conduction, we evoked one spike with somatic current injection $100 \mathrm{~ms}$ after the onset of glutamate uncaging. Interleaved control spikes were not paired with glutamate uncaging. Glutamate uncaging did not change the amplitude of spikes recorded in the projection process (100.2 \pm $2.0 \%$ of control, $p>0.05, n=8$ neurons), but did induce a small yet significant increase in their width $(103.7 \pm 1.0 \%$ of control, $p=0.016$, Wilcoxon sign ranked test; $n=8$; Fig. 7 ). Scanning the uncaging laser without applying MNI-glutamate did not change spike parameters ( spike height $=98.0 \pm 3.2 \%$ control, $p>0.05$; spike width $=98.8 \pm 2.1 \%$ control, $p>0.05, n=7$ neurons).

\section{Discussion}

We report here a highly unexpected scenario in which GnRH neurons elaborate long distance projections with blended dendritic and axonal properties to control GnRH secretion into the median eminence. Specifically, the projection has a spike initiation site and actively conducts action potentials to the median eminence. However, it can also simultaneously receive and integrate synaptic inputs along its entire length thereby regulating the excitability of the neuron. We have termed this unique projection, exhibiting blended properties of a dendrite and axon, the "dendron."

In recent years, studies have begun to challenge the classical roles attributed to dendrites and axons. It is now clear that dendrites of many different neurons are capable of actively conducting action potentials (Stuart et al., 1997) and releasing neurotransmitters (Regehr et al., 2009). While dendritic transmitter
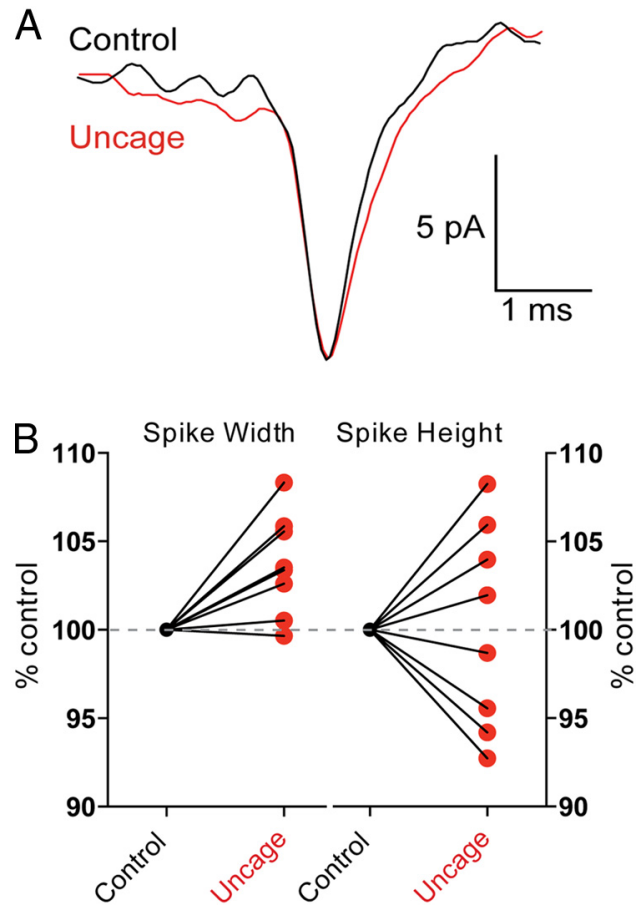

Figure 7. Modulation of conducted spikes by glutamate receptor activation. $\boldsymbol{A}$, Spikes were recorded from a $\mathrm{GnRH}$ neuron projection with an on-cell recording electrode. Action potentials were evoked by somatic current injection either alone (black) or simultaneously with glutamate uncaging (red). $\boldsymbol{B}$, Glutamate uncaging produced a significant broadening of the spike recorded in the projection process when compared with a control spike ( $p<0.05, n=8$ neurons), with no change in spike amplitude ( $p>0.05, n=8$ neurons).

release is important for the tuning of excitability in many neurons, the primary projection/output structure of these neurons is still the axon. It has also been recently shown that axons can transmit graded subthreshold potentials over long distances in addition to binary action potentials (Alle and Geiger, 2006; Shu et al., 2006). If these graded potentials are sufficiently large, they can modify the release from the presynaptic nerve terminals and hence the flow of information from one cell to the next. In this scenario, the graded potentials originate first in the somatodendritic compartment before passing into and along the axon. Although it is well established that axo-axonic connections can occur at the presynaptic terminal and axon hillock of the postsynaptic cell (Howard et al., 2005), there is little evidence that axons innervate intermediary axonal elements.

In the examples given above, it is important to note that while the axon and dendrite appear to be sharing functions, these neurons still possess discrete structures that either primarily receive afferent inputs (i.e., dendrites) or primarily conduct output signals (i.e., the axon). This is in stark contrast to the GnRH neuron dendron where a single structure performs both tasks simultaneously. The observation that these neurons and their processes do not exhibit detectable classical axonal or dendritic markers provides further support for the notion that they are structurally and functionally different to other neuronal processes in the mammalian brain. It is interesting to speculate that the unique morphology of the GnRH neurons may result from their embryonic origin in the nose (Schwanzel-Fukuda and Pfaff, 1989; Wray et al., 1989). While we did not observe the expression of several standard neuronal markers in adult GnRH neurons, previous work has shown that GnRH neurons in embryonic explant cultures do possess transcripts for $\beta$-tubulin (Sharifi et al., 2002). 
This suggests that the expression level in the adult is either below our level of detection or that some of these proteins are developmentally downregulated.

The one marker that GnRH neurons showed consistent labeling for was Ankyrin G. This is an adaptor protein that acts to concentrate voltage-gated $\mathrm{Na}^{+}$and other membrane proteins at the initial segment of neurons (Kordeli et al., 1995). Ankyrin G labeling was found at a distance of $89 \pm 30 \mu \mathrm{m}$ from the soma in the projection process heading toward the median eminence. This location fits with our previous data showing that the largest influx of $\mathrm{Na}^{+}$during a burst of action potentials occurs in this region indicating that this is the likely site of spike initiation in GnRH neurons (Iremonger and Herbison, 2012). Only one region of Ankyrin G labeling was found in each GnRH neuron. This is also consistent with our previous and current electrophysiological data suggesting that only a single site of spike initiation exists in each GnRH neuron.

Given the highly unusual situation of finding $\mathrm{GnRH}$ neurons to have a dendron, we questioned whether this might be an overlooked, general feature of all hypophysiotropic neuroendocrine neurons controlling pituitary gland secretion. We note here that the arcuate dopaminergic neurons projecting to the median eminence to control prolactin secretion, exhibit normal axonal and dendritic morphologies. Thus, it would seem that not all hypophysiotropic neurons have dendrons but we cannot, as yet, exclude the existence of the dendron in other specific hypophysiotropic neuroendocrine neurons.

Whereas the cell bodies of GnRH neurons are scattered throughout the basal forebrain, the dendrons of GnRH neurons become highly concentrated around the median eminence. We show here that these distal dendrons are responsive to GABA and glutamate. This may provide an ideal location for afferent axons to modulate the excitability of multiple GnRH neuron dendrons and, thereby, potentially synchronize their secretion. Indeed, we speculate that the excitability of $\mathrm{GnRH}$ neurons may be regulated at two independent levels. Specifically, synaptic inputs that impinge close to the spike initiation site in the proximal dendron will have the largest impact on spike patterning, while distal synaptic inputs on the distal dendron within and near the median eminence would be predicted to fine-tune neurosecretion by directly depolarizing or hyperpolarizing the dendron close to the neurosecretory terminals. Regulation of the membrane potential close to the sites of neurosecretion may regulate the opening of voltage-gated calcium channels or as we show here, regulate the shape of propagating action potentials (Shu et al., 2006; Kole et al., 2007). Indeed, previous work has shown that glutamateevoked spike broadening can result in a significant enhancement of neurotransmitter release if it occurs in close enough proximity to the presynaptic nerve terminal (Sasaki et al., 2011). This may well be the case for GnRH neurons although it has not been possible, as yet, to define the impact of spike widening in the $\mathrm{GnRH}$ neuron distal dendron upon $\mathrm{GnRH}$ secretion from the median eminence. Intriguingly, we note here that GABA exerts a depolarizing influence upon the dendron in adults, as is found for the GnRH neuron soma (Herbison and Moenter, 2011).

The definition here of the dendron may provide answers to some perplexing issues in the GnRH neurobiology field. First, investigators have reported that acute mediobasal hypothalamic or median eminence fragment preparations continue to secrete $\mathrm{GnRH}$ in an episodic fashion in vitro despite the observation that these preparations are unlikely to contain any GnRH neuron cell bodies (Rasmussen, 1993; Bourguignon et al., 1997; Purnelle et al., 1997). These preparations would undoubtedly contain GnRH neuron dendrons that could, as noted above, potentially underlie synchronized GnRH secretion. Second, many studies have demonstrated that neurotransmitters can modulate the secretion of $\mathrm{GnRH}$ from median eminence/basal hypothalamic explants in vitro despite the absence of ultrastructural evidence for presynaptic elements contacting $\mathrm{GnRH}$ nerve terminals in most species (Herbison, 2006). It is often considered that these actions occur as a result of volume conduction. However, another possibility is that these responses may result from neurotransmitter activation of the distal dendron in these preparations. In the future, it will be important to establish the full range of neurotransmitter and neuropeptide receptors present on the distal dendron.

The initial discovery that GnRH neurons exhibited extremely long dendrites was intriguing but also puzzling as to why they should do so, and how synaptic information could be integrated over such long distances (Campbell and Suter, 2010). A reassessment of the location and orientation of reconstructed dendrites in these early studies (Campbell et al., 2005, 2009) indicates that they were almost certainly dendronic projections to the median eminence. This indicates that spine density on the proximal dendron is plastic (Cottrell et al., 2006; Chan et al., 2011) and that these dendrons bundle together and receive shared synapses within the preoptic area (Campbell et al., 2009). This provides yet further possibilities for direct synchronization of GnRH neuron output.

In conclusion, we demonstrate that GnRH neurons extend a process to the median eminence that functions simultaneously as an axon and dendrite. The dendron allows GnRH neurons to integrate synaptic information along its entire projection, including sites close to neurosecretory terminals. This unique morphology allows a much greater range of dynamic control over GnRH neuron secretion into the median eminence and represents a new paradigm for communication in the mammalian brain.

\section{References}

Alle H, Geiger JR (2006) Combined analog and action potential coding in hippocampal mossy fibers. Science 311:1290-1293. CrossRef Medline

Binder LI, Frankfurter A, Rebhun LI (1985) The distribution of tau in the mammalian central nervous system. J Cell Biol 101:1371-1378. CrossRef Medline

Bourguignon JP, Gérard A, Purnelle G, Czajkowski V, Yamanaka C, Lemaître M, Rigo JM, Moonen G, Franchimont P (1997) Duality of glutamatergic and GABAergic control of pulsatile GnRH secretion by rat hypothalamic explants: I. Effects of antisense oligodeoxynucleotides using explants including or excluding the preoptic area. J Neuroendocrinol 9:183-191. Medline

Campbell RE, Suter KJ (2010) Redefining the gonadotrophin-releasing hormone neurone dendrite. J Neuroendocrinol 22:650-658. Medline

Campbell RE, Han SK, Herbison AE (2005) Biocytin filling of adult gonadotropin-releasing hormone neurons in situ reveals extensive, spiny, dendritic processes. Endocrinology 146:1163-1169. Medline

Campbell RE, Gaidamaka G, Han SK, Herbison AE (2009) Dendrodendritic bundling and shared synapses between gonadotropin-releasing hormone neurons. Proc Natl Acad Sci U S A 106:10835-10840. CrossRef Medline

Chan H, Prescott M, Ong Z, Herde MK, Herbison AE, Campbell RE (2011) Dendritic spine plasticity in gonadotropin-releasing hormone $(\mathrm{GnRH})$ neurons activated at the time of the preovulatory surge. Endocrinology 152:4906-4914. CrossRef Medline

Chung CY, Koprich JB, Siddiqi H, Isacson O (2009) Dynamic changes in presynaptic and axonal transport proteins combined with striatal neuroinflammation precede dopaminergic neuronal loss in a rat model of AAV alpha-synucleinopathy. J Neurosci 29:3365-3373. CrossRef Medline

Constantin S, Piet R, Iremonger K, Hwa Yeo S, Clarkson J, Porteous R, Herbison AE (2012) GnRH neuron firing and response to GABA in vitro depend on acute brain slice thickness and orientation. Endocrinology 153:3758-3769. CrossRef Medline 
Cottrell EC, Campbell RE, Han SK, Herbison AE (2006) Postnatal remodeling of dendritic structure and spine density in gonadotropin-releasing hormone neurons. Endocrinology 147:3652-3661. CrossRef Medline

Herbison AE (2006) Physiology of the GnRH neuronal network. In: Knobil and Neill's physiology of reproduction, Ed 3 (Neill JD, ed), pp 1415-1482. San Diego: Academic.

Herbison AE, Moenter SM (2011) Depolarising and hyperpolarising actions of $\mathrm{GABA}(\mathrm{A})$ receptor activation on gonadotrophin-releasing hormone neurones: towards an emerging consensus. J Neuroendocrinol 23:557569. CrossRef Medline

Howard A, Tamas G, Soltesz I (2005) Lighting the chandelier: new vistas for axo-axonic cells. Trends Neurosci 28:310-316. CrossRef Medline

Huber G, Matus A (1984) Differences in the cellular distributions of two microtubule-associated proteins, MAP1 and MAP2, in rat brain. J Neurosci 4:151-160. Medline

Iremonger KJ, Herbison AE (2012) Initiation and propagation of action potentials in gonadotropin-releasing hormone neuron dendrites. J Neurosci 32:151-158. CrossRef Medline

Kole MH, Letzkus JJ, Stuart GJ (2007) Axon initial segment Kvl channels control axonal action potential waveform and synaptic efficacy. Neuron 55:633-647. CrossRef Medline

Kordeli E, Lambert S, Bennett V (1995) AnkyrinG. A new ankyrin gene with neural-specific isoforms localized at the axonal initial segment and node of Ranvier. J Biol Chem 270:2352-2359. CrossRef Medline

Levine JE (2003) Gonadotropin-releasing hormone (GnRH). In: Encyclopedia of hormones (Henry H, Norman A, eds), pp 157-165. San Diego: Academic.

Moody SA, Quigg MS, Frankfurter A (1989) Development of the peripheral trigeminal system in the chick revealed by an isotype-specific anti-betatubulin monoclonal antibody. J Comp Neurol 279:567-580. CrossRef Medline

Plant TM (2008) Hypothalamic control of the pituitary-gonadal axis in higher primates: key advances over the last two decades. J Neuroendocrinol 20:719-726. CrossRef Medline

Purnelle G, Gérard A, Czajkowski V, Bourguignon JP (1997) Pulsatile secretion of gonadotropin-releasing hormone by rat hypothalamic explants without cell bodies of GnRH neurons. Neuroendocrinology 66:305-312. CrossRef Medline

Rasmussen DD (1993) Episodic gonadotropin-releasing hormone release from the rat isolated median eminence in vitro. Neuroendocrinology 58:511-518. CrossRef Medline

Regehr WG, Carey MR, Best AR (2009) Activity-dependent regulation of synapses by retrograde messengers. Neuron 63:154-170. CrossRef Medline

Roberts CB, Campbell RE, Herbison AE, Suter KJ (2008) Dendritic action potential initiation in hypothalamic gonadotropin-releasing hormone neurons. Endocrinology 149:3355-3360. CrossRef Medline
Sasaki T, Matsuki N, Ikegaya Y (2011) Action-potential modulation during axonal conduction. Science 331:599-601. CrossRef Medline

Schwanzel-Fukuda M, Pfaff DW (1989) Origin of luteinizing hormonereleasing neurons. Nature 338:161-164. CrossRef Medline

Setou M, Nakagawa T, Seog DH, Hirokawa N (2000) Kinesin superfamily motor protein KIF17 and mlin-10 in NMDA receptor-containing vesicle transport. Science 288:1796-1802. CrossRef Medline

Sharifi N, Reuss AE, Wray S (2002) Prenatal LHRH neurons in nasal explant cultures express estrogen receptor beta transcript. Endocrinology 143: 2503-2507. CrossRef Medline

Shu Y, Hasenstaub A, Duque A, Yu Y, McCormick DA (2006) Modulation of intracortical synaptic potentials by presynaptic somatic membrane potential. Nature 441:761-765. CrossRef Medline

Silverman A, Livne I, Witkin JW (1994) The gonadotrophin-releasing hormone $(\mathrm{GnRH})$, neuronal systems: immunocytochemistry and in situ hybridization. In: The physiology of reproduction, Ed 2 (Knobil E, Neill JD, eds), pp 1683-1706. New York: Raven.

Spergel DJ, Krüth U, Hanley DF, Sprengel R, Seeburg PH (1999) GABA-and glutamate-activated channels in green fluorescent protein-tagged gonadotropin-releasing hormone neurone in transgenic mice. J Neurosci 19:2037-2050. Medline

Sternberger LA, Sternberger NH (1983) Monoclonal antibodies distinguish phosphorylated and nonphosphorylated forms of neurofilaments in situ. Proc Natl Acad Sci U S A 80:6126-6130. CrossRef Medline

Stuart G, Spruston N, Sakmann B, Häusser M (1997) Action potential initiation and backpropagation in neurons of the mammalian CNS. Trends Neurosci 20:125-131. CrossRef Medline

Terasawa E, Fernandez DL (2001) Neurobiological mechanisms of the onset of puberty in primates. Endocr Rev 22:111-151. CrossRef Medline

Van Wart A, Trimmer JS, Matthews G (2007) Polarized distribution of ion channels within microdomains of the axon initial segment. J Comp Neurol 500:339-352. CrossRef Medline

Witkovsky P, Gábriel R, Krizaj D (2008) Anatomical and neurochemical characterization of dopaminergic interplexiform processes in mouse and rat retinas. J Comp Neurol 510:158-174. CrossRef Medline

Wray S, Grant P, Gainer H (1989) Evidence that cells expressing luteinizing hormone-releasing hormone mRNA in the mouse are derived from progenitor cells in the olfactory placode. Proc Natl Acad Sci U S A 86:81328136. CrossRef Medline

Ybarra N, Hemond PJ, O’Boyle MP, Suter KJ (2011) Spatially selective, testosterone-independent remodeling of dendrites in gonadotropinreleasing hormone $(\mathrm{GnRH})$ neurons prepubertally in male rats. Endocrinology 152:2011-2019. CrossRef Medline

Zhao S, Ting JT, Atallah HE, Qiu L, Tan J, Gloss B, Augustine GJ, Deisseroth K, Luo M, Graybiel AM, Feng G (2011) Cell type-specific channelrhodopsin-2 transgenic mice for optogenetic dissection of neural circuitry function. Nature Methods 8:745-752. CrossRef Medline 